\title{
Synthesis and Characterization of Some New 1-(3-(heterocyclic-2- yl)-4,5-dihydroisoxazol-5-yl)Pentane-1,2,3,4,5-Pentaol Derivatives from New Chalcone
}

\author{
Mays Kamil Kutafh* Abbas F. Abbas Khansa Abdul Razzaq Ali Al-Assadi \\ Collage of Science University of Basrah, Basrah - Iraq
}

\begin{abstract}
The synthesis and characterization of some novel chalcone and isoxazole derivatives has been presented. Isoxazoles (D-F) have been prepared from chalcones (A-C) by treating with hydroxylamine hydrochloride. The structure of isoxazoles has been characterized by spectral analysis by FT-IR and ${ }^{1} \mathrm{H}$ NMR spectroscopy.
\end{abstract}

Keywords: isoxazole chalcone, heterocyclic

DOI: $10.7176 / \mathrm{CMR} / 12-1-02$

Publication date: January $31^{\text {st }} 2020$

\section{Introduction}

Heterocyclic compounds are very widely distributed in nature, and are essential to life in various ways. Particularly these compounds are important because of the wide variety of physiological activities associated with this class of substances. Heterocyclic rings are present in several compounds, e. g, most of the members of vitamin B complex, antibiotics, chlorophyll, haemin, other plant pigments, amino acids and proteins, drugs, dye stuffs, enzymes, the genetic material DNA etc.

The paramount importance of heterocycles in nature product chemistry and pharmacology constantly drive the search for new methods for the construction of heterocyclic unit viz., isoxazoles and pyrazoles. These isoxazoles and pyrazoles were prepared from chalcones which are important intermediate products and they also possess biological and pharmacological activities [1].

Isoxazoles possess interesting medicinal [2] properties and have some industrial utility [3]. Many biologically active isoxazoles and reduced isoxazole derivatives have been reported, viz., the naturally occurring antituberculosis, antibiotic cycloserine, the mono amine oxidase inhibitor: isocarboxazid, useful in psychotherapy and Isoxazole steroids show anabolic activity, eg., Denazole [4]. The CNS active isoxazoles, ibotenic acid, muscimol and muscazone are isolated from amanita muscaria and other amanita species. Isoxazole derivatives were used as inhibitors for ulcers [5], lipoxygenase [6], acetyl choline esterase [7]. 3-Substituted 5-methylthio isoxazoles were found to exhibit anthelmintic activity [8]. Spiroisoxazolines [9] and benzofuroisoxazoles [10] were used as anti-convergents. 5-Amino-3-methyl-4-ureidoisoxazoles were found to exhibit anti leukemic activity [11].

\section{Experimental}

General. IR spectra recorded on FT.IR SHIMADZU model $8400, .{ }^{1} \mathrm{H}$ NMR spectra were acquired with a SHIMADZU ( ${ }^{1} \mathrm{HNMR}$ : $400 \mathrm{MHz}$ ) (University of Tahran ,Iran). The chemical shifts were referenced to tetra methyl silane (TMS) as an internal reference. Mass spectra were acquired with a SHIMADZU (University of Tahran ,Iran).

\section{Synthesis of chalcone derivatives (A-C)}

General procedure. A mixture of glucose $(0.05)$ mole with $(0.005)$ mole of 2-acetyl heterocyclic derivatives were dissolved in ethanolic sodium hydroxide $(10 \mathrm{ml})$ the mixture was stering for $3 \mathrm{hrs}$. . The precipitate obtained was filtered, washed and recrystallized from ethanol. To afford the pure products $(\mathbf{A}-\mathbf{C})$.

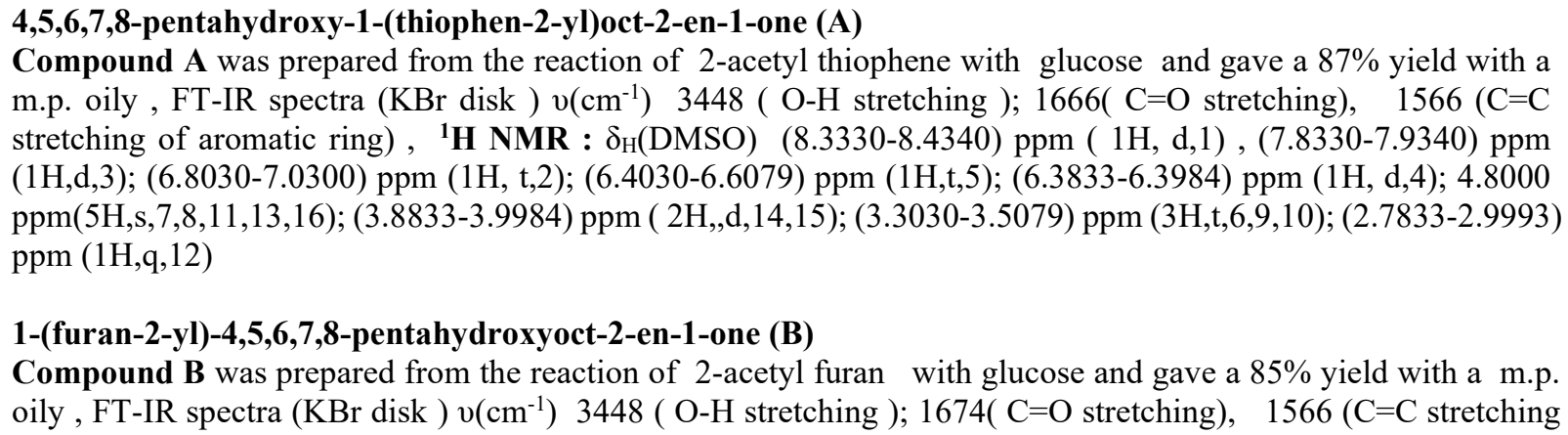
m.p. oily, FT-IR spectra ( $\mathrm{KBr}$ disk ) v $\left(\mathrm{cm}^{-1}\right) 3448$ ( O-H stretching ); 1666( $\mathrm{C}=\mathrm{O}$ stretching), $1566(\mathrm{C}=\mathrm{C}$ stretching of aromatic ring), ${ }^{1} \mathbf{H}$ NMR : $\delta_{\mathrm{H}}(\mathrm{DMSO})(8.3330-8.4340) \mathrm{ppm}(1 \mathrm{H}, \mathrm{d}, 1),(7.8330-7.9340) \mathrm{ppm}$ $(1 \mathrm{H}, \mathrm{d}, 3) ;(6.8030-7.0300)$ ppm $(1 \mathrm{H}, \mathrm{t}, 2) ;(6.4030-6.6079) \mathrm{ppm}(1 \mathrm{H}, \mathrm{t}, 5) ;(6.3833-6.3984) \mathrm{ppm}(1 \mathrm{H}, \mathrm{d}, 4) ; 4.8000$ $\operatorname{ppm}(5 \mathrm{H}, \mathrm{s}, 7,8,11,13,16) ;(3.8833-3.9984) \mathrm{ppm}(2 \mathrm{H}, \mathrm{d}, 14,15) ;(3.3030-3.5079) \mathrm{ppm}(3 \mathrm{H}, \mathrm{t}, 6,9,10) ;(2.7833-2.9993)$ $\operatorname{ppm}(1 \mathrm{H}, \mathrm{q}, 12)$

1-(furan-2-yl)-4,5,6,7,8-pentahydroxyoct-2-en-1-one (B)

Compound $\mathbf{B}$ was prepared from the reaction of 2 -acetyl furan with glucose and gave a $85 \%$ yield with a m.p. oily, FT-IR spectra (KBr disk ) v $\left(\mathrm{cm}^{-1}\right) 3448$ ( O-H stretching $) ; 1674(\mathrm{C}=\mathrm{O}$ stretching), $1566(\mathrm{C}=\mathrm{C}$ stretching 
of aromatic ring) , ${ }^{1} \mathbf{H}$ NMR : $\delta_{\mathrm{H}}(\mathrm{DMSO}) \quad(8.7330-8.8340) \mathrm{ppm}(1 \mathrm{H}, \mathrm{d}, 1),(8.3330-8.4340) \mathrm{ppm}(1 \mathrm{H}, \mathrm{d}, 3)$; (8.0030-8.2300) ppm (1H,t,2); (6.4030-6.6079) ppm (1H, t,5); (6.3833-6.3984) ppm (1H,d,4); 4.8000 $\operatorname{ppm}(5 \mathrm{H}, \mathrm{s}, 7,8,11,13,16) ;(3.8833-3.9984) \operatorname{ppm}(2 \mathrm{H}, \mathrm{d}, 14,15) ;(3.3030-3.5079) \operatorname{ppm}(3 \mathrm{H}, \mathrm{t}, 6,9,10) ;(2.7833-2.9993)$ ppm $(1 \mathrm{H}, \mathrm{q}, 12)$

\section{4,5,6,7,8-pentahydroxy-1-(1H-pyrrol-2-yl)oct-2-en-1-one (C)}

Compound $\mathbf{C}$ was prepared from the reaction of 2-acetyl pyrrole with glucose and gave a $80 \%$ yield with a m.p. $(125-127)^{0} \mathrm{c}, \mathrm{FT}-\mathrm{IR}$ spectra $(\mathrm{KBr}$ disk $) \mathrm{v}\left(\mathrm{cm}^{-1}\right) 3417$ ( O-H stretching ); 1662 ( $\mathrm{C}=\mathrm{O}$ stretching), $1600(\mathrm{C}=\mathrm{C}$ stretching of aromatic ring), ${ }^{\mathbf{1}} \mathbf{H}$ NMR : $\delta_{\mathrm{H}}(\mathrm{DMSO}) 11.3000 \mathrm{ppm}(1 \mathrm{H}, \mathrm{s}, 17) ;(7.7330-7.8340) \mathrm{ppm}(1 \mathrm{H}, \mathrm{d}, 1)$, (7.4330-7.5340) ppm (1H, d ,3); (6.8030-7.0300) ppm (1H,t,2); (6.4030-6.6079) ppm (1H, t,5); (6.3833-6.3984) ppm $(1 \mathrm{H}, \mathrm{d}, 4) ; 4.8000 \mathrm{ppm}(5 \mathrm{H}, \mathrm{s}, 7,8,11,13,16) ;(3.8833-3.9984)$ ppm ( $2 \mathrm{H}, \mathrm{d}, 14,15)$; (3.3030-3.5079) ppm $(3 \mathrm{H}, \mathrm{t}, 6,9,10) ;(2.7833-2.9993) \mathrm{ppm}(1 \mathrm{H}, \mathrm{q}, 12)$

\section{Synthesis of isoxazole derivatives (D-F)}

General procedure. A mixture of Chalcone $(\mathbf{A}-\mathbf{C}) \backslash(0.05 \mathrm{~mol})$ with hydroxylamine hydrochloride $(0.05 \mathrm{~mol})$ were dissolved in $10 \mathrm{ml}$ of ethanol and added $5 \mathrm{ml}$ of glacial acetic acid was reflux overnight. The precipitate obtained was filtered, washed and recrystallized from ethanol. The progress of the reaction was monitored by TLC (ethyl toluene /ethanol, 8:2). The EtOH was removed under reduced pressure and the residue was recrystalized from $\mathrm{EtOH}$ to afford the pure products (D-F).

\section{1-(3-(thiophen-2-yl)-4,5-dihydroisoxazol-5-yl)pentane-1,2,3,4,5-pentaol (D)}

Compound D was prepared from the reaction of 4,5,6,7,8-pentahydroxy-1-(thiophen-2-yl)oct-2-en-1-one with hydroxylamine hydrochloride and gave a $80 \%$ yield with a m.p. $>300^{\circ} \mathrm{c}$ decomposition , FT-IR spectra (KBr disk ) $v\left(\mathrm{~cm}^{-1}\right) 3383(\mathrm{O}-\mathrm{H}$ stretching $) ; 1612(\mathrm{C}=\mathrm{N}$ stretching of isoxazole ring ), $1265(\mathrm{C}-\mathrm{N}$ stretching of isoxazole ring), 1110 ( $\mathrm{N}-\mathrm{O}$ stretching of isoxazole ring $) ;{ }^{1} \mathbf{H}$ NMR : $\delta_{\mathrm{H}}(\mathrm{DMSO})(7.9833-8.0984) \mathrm{ppm}(1 \mathrm{H}, \mathrm{d}, 1),(7.4833-$ 7.5984) ppm (1H,d,3); (7.1030-7.3079) ppm (1H, t,2); $4.8000 \mathrm{ppm}(5 \mathrm{H}, \mathrm{s}, 8,10,12,14,17) ;(3.0833-3.0984) \mathrm{ppm}$ (2H,d, 15,16); (3.4030-3.6300) ppm (3H,t,7,9,11); (2.9833-3.0993) ppm (1H,q,13); (2.1833- 2.4000) ppm (1H,q,4); (1.4833-1.5984) ppm ( $2 \mathrm{H}, \mathrm{d}, 5,6)$.

\section{1-(3-(furan-2-yl)-4,5-dihydroisoxazol-5-yl)pentane-1,2,3,4,5-pentaol (E)}

Compound $\mathbf{E}$ was prepared from the reaction of 1-(furan-2-yl)-4,5,6,7,8-pentahydroxyoct-2-en-1-one with hydroxylamine hydrochloride and gave a $87 \%$ yield with a m.p. $=(90-92){ }^{0} \mathrm{c}$, FT-IR spectra $(\mathrm{KBr}$ disk $) v\left(\mathrm{~cm}^{-1}\right)$ 3448 ( O-H stretching ); 1643( $\mathrm{C}=\mathrm{N}$ stretching of isoxazole ring ), 1255 (C-N stretching of isoxazole ring), 1122 ( N-O stretching of isoxazole ring ); ${ }^{1} \mathbf{H}$ NMR : $\delta_{\mathrm{H}}(\mathrm{DMSO})(7.9833-8.0984) \mathrm{ppm}(1 \mathrm{H}, \mathrm{d}, 1),(6.8833-6.9984)$ ppm (1H,d,3); (6.4030-6.6079) ppm (1H, t,2); 4.8000 ppm $(5 \mathrm{H}, \mathrm{s}, 8,10,12,14,17) ; \quad$ (3.0833-3.0984) ppm $(2 \mathrm{H}, \mathrm{d}, 15,16) ;(3.4030-3.6300) \mathrm{ppm}(3 \mathrm{H}, \mathrm{t}, 7,9,11) ;(2.9833-3.0993) \mathrm{ppm}(1 \mathrm{H}, \mathrm{q}, 13) ;(2.1833-2.4000) \mathrm{ppm}(1 \mathrm{H}, \mathrm{q}, 4)$; (1.4833-1.5984) ppm ( $2 \mathrm{H}, \mathrm{d}, 5,6)$.

\section{1-(3-(1H-pyrrol-2-yl)-4,5-dihydroisoxazol-5-yl)pentane-1,2,3,4,5-pentaol (F)}

Compound $\mathbf{F}$ was prepared from the reaction of 4,5,6,7,8-pentahydroxy-1-(1H-pyrrol-2-yl)oct-2-en-1-one with hydroxylamine hydrochloride and gave a $79 \%$ yield with a m.p. $>300{ }^{\circ} \mathrm{c}$ decomposition , FT-IR spectra $(\mathrm{KBr}$ disk ) $v\left(\mathrm{~cm}^{-1}\right) 3448$ ( O-H stretching ); 1627( $\mathrm{C}=\mathrm{N}$ stretching of isoxazole ring ), $1250(\mathrm{C}-\mathrm{N}$ stretching of isoxazole ring) , 1168 ( N-O stretching of isoxazole ring ); ${ }^{1} \mathbf{H}$ NMR : $\delta_{\mathrm{H}}(\mathrm{DMSO}) 11.200 \mathrm{ppm}(1 \mathrm{H}, \mathrm{S}, 18) ; \quad$ (7.4533-8.4984) ppm $(1 \mathrm{H}, \mathrm{d}, 1),(6.8833-6.9984) \mathrm{ppm}(1 \mathrm{H}, \mathrm{d}, 3) ;(6.4030-6.6079) \mathrm{ppm}(1 \mathrm{H}, \mathrm{t}, 2) ; 4.8000 \mathrm{ppm}(5 \mathrm{H}, \mathrm{s}, 8,10,12,14,17)$; (3.0833-3.0984) ppm ( 2H,,d,15,16); (3.4030-3.6300) ppm (3H,t,7,9,11); (2.9833-3.0993) ppm (1H,q, 13); (2.18332.4000) ppm (1H,q,4); (1.4833-1.5984) ppm ( $2 \mathrm{H}, \mathrm{d}, 5,6)$.

\section{Results and discussion}

Treatment of 2-acetyl heterocyclic derivatives with glucose in boiling ethanol gave chalcone derivatives (A-C) (scheme 1) in (80-87)\% yield. The structures of these derivatives were characterized from their FT-IR and ${ }^{1} \mathrm{H}$ NMR spectra. The FT-IR spectra of chalcone compounds (A-C) were characterized by the appearance of the absorption band of chalcone that was attributed to the $(C=C)$ stretching which appeared at $(1566-1600) \mathrm{cm}^{-1}$ These fact confirmed the correct expected chemical structure of these compounds. All the IR spectra of chalcone compounds (A-C) showed a band at $(1662-1674) \mathrm{cm}^{-1}$ which related to $(\mathrm{C}=\mathrm{O})$ stretching of chalcone, $\mathrm{The} \mathrm{OH}$ stretching of glucose showed a band within the range $(3417-3448) \mathrm{cm}^{-1}$.

The ${ }^{1} \mathrm{H}$ NMR spectra of chalcone derivatives (A-C) were characterized [12-15] by the presence showed triplet signals within range (6.4030-6.6079) ppm which appeared to proton in (5) position. The proton in 4 position showed doublet signals within the range (6.3833-6.3984) ppm. The protons of aromatic rings (heterocyclic rings) showed doublet signals within the range $(8.7330-8.8340) \mathrm{ppm}$ which appeared to protons in (1) position because 
interaction with proton in (2) position, the proton in position (3) showed doublet signals within the range (8.4330$8.5340) \mathrm{ppm}$ because interaction with proton in (2) position. While the proton in position (2) showed triplet signals within the range (8.0030-8.2300) ppm because interaction with protons in ( 1 and 3$)$ positions. The protons of hydroxyl groups of glucose showed singlet signal within the range $4.800 \mathrm{ppm}$ which appeared to the protons in $(7,8,11,13$ and 16)) positions. While the aliphatic protons showed doublet signals for two protons in position (14 and 15) at (3.8833-3.9984) ppm, but three protons in positions ( 6,9 and 10) showed triplet signals within the range (3.3030-3.5079) ppm, the other two protons in position (12) showed quartet signals within the range ( 2.7833-2.9993) ppm. While the peak of solvent (DMSO) showed singlet signal within the range $2.50 \mathrm{ppm}$.

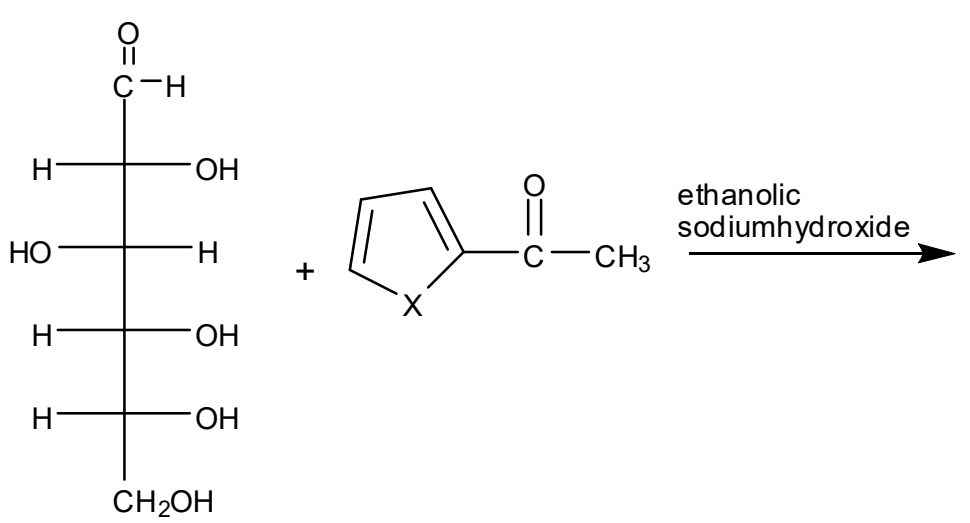

Scheme (1)

Treatment of chalcone derivatives (A-C) with hydroxylamine hydrochloride in boiling ethanol and glacial acetic acid gave 1-(3-(heterocyclic-2-yl)-4,5-dihydroisoxazol-5-yl)pentane-1,2,3,4,5-pentaol derivatives (D-F) (scheme 2) in (79-87)\% yield. The structures of these derivatives were characterized from their FT-IR and ${ }^{1} \mathrm{H}$ NMR spectra. The FT-IR spectra of chalcone compounds (A-C) were characterized by the disappearance of the absorption band of chalcone that was attributed to the $(\mathrm{C}=\mathrm{O})$ stretching which appeared at $(1662-1674) \mathrm{cm}^{-1}$, and disappearance of the absorption band of chalcone that attributed to the $(\mathrm{C}=\mathrm{C})$ stretching which appeared at $(1566$ 1600) $\mathrm{cm}^{-1}$.

These fact confirmed the correct expected chemical structure of these compounds. All the IR spectra of 1-(3(heterocyclic-2-yl)-4,5-dihydroisoxazol-5-yl)pentane-1,2,3,4,5-pentaol derivatives (D-F) showed a band at (1612$1643) \mathrm{cm}^{-1}$ which related to $(\mathrm{C}=\mathrm{N})$ stretching of isoxazole ring , and showed band at $(1250-1265) \mathrm{cm}^{-1}$ which related to $(\mathrm{C}-\mathrm{N})$ stretching of isoxazole ring. But the $(\mathrm{N}-\mathrm{O})$ stretching band showed at $(1110-1168) \mathrm{cm}^{-1}$. The $\mathrm{OH}$ stretching of glucose showed a band within the range $(3383-3448) \mathrm{cm}^{-1}$.

The ${ }^{1} \mathrm{H}$ NMR spectra of 1-(3-(heterocyclic-2-yl)-4,5-dihydroisoxazol-5-yl)pentane-1,2,3,4,5-pentaol derivatives (D-F) were characterized [12-15] by the presence showed quartet signals within range $(2.1833-2.4000)$ ppm which appeared to proton in (4) position. While the two proton in (5 and 6) positions showed doublet signals within the range (1.4833-1.5984) ppm. The protons of aromatic rings (heterocyclic rings) showed doublet signals within the range (7.4533-8.4984) ppm which appeared to protons in (1) position because interaction with proton in (2) position, the proton in position (3) showed doublet signals within the range (6.8833-6.9984) ppm because interaction with proton in (2) position. While the proton in position (2) showed triplet signals within the range (6.4030-6.6079) ppm because interaction with protons in (1 and 3) positions. The protons of hydroxyl groups of glucose showed singlet signal within the range $4.800 \mathrm{ppm}$ which appeared to the protons in $(8,10,12,14$ and 17$))$ positions. While the aliphatic protons showed doublet signals for two protons in position (15 and 16) at (3.0833$3.0984) \mathrm{ppm}$, but three protons in positions ( 7,9 and 11) showed triplet signals within the range $(3.4030-3.6300)$ $\mathrm{ppm}$, the other two protons in position (13) showed quartet signals within the range (2.9833-3.0993) ppm. While the peak of solvent (DMSO) showed singlet signal within the range $2.50 \mathrm{ppm}$. 
<smiles></smiles>

$\mathrm{X}=\mathrm{S}, \mathrm{O}, \mathrm{NH}$

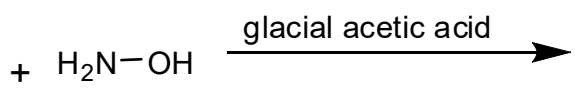

Scheme (2)

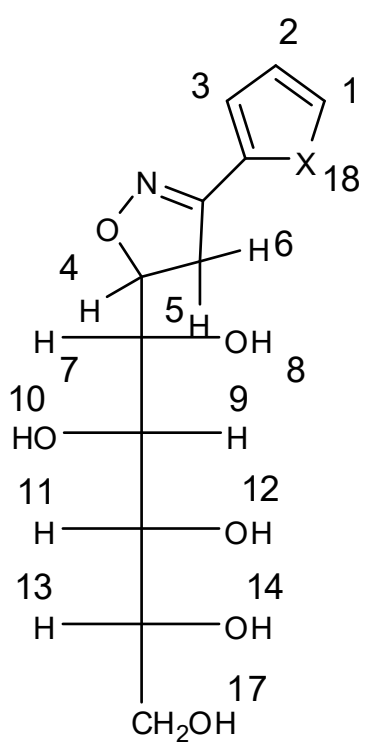

15,16

\section{References}

[1] D. N. Dhar, The Chemistry of Chaclcones and related Compounds, John Wiley \& Sons Inc., 1981.

[2] C. O. Wilson; O. Gisvold, Text book of Organic Medicinal and Pharmaceutical Chemistry, Lippincott Williams \& Wilkins Pitman, London, 1966.

[3] K. H. Wunsche; A. Button, J. Adv. Heterocycl. Chem., 1967, 8, 277.

[4] N. K. Kochetkov; S. D. Sokolov, Adv. Heterocycl. Chem., 1963, 2, 365.

[5] Yukio Hasegawa; Suto Michitaka, Jpn. Kokai Tokkyo Koho JP, 1996, CA 124.

[6] Suzuki, Masahiro; Nozaki, Kensi, PCT Int., 1994, CA 121.

[7] Takasugu, Hisashi; Kuno, atsushi, PCT Int., 1994, CA 122.

[8] A.K. Benerjee; S. Bandyopadhyaya, Arzeim-Forschi., 1994, 44(7), 863.

[9] Zen, Akinosuku; Hiroya, kyoko, Jpn. Kokai Tokkyo Koho JP, 1993, CA 120.

[10] Zen, Akinosuki; Hiroya, kyoko, Jpn. Kokai Tokkyo Koho JP, 1994, CA 120.

[11] S. Ryng; D. Dec, Pharmazie, 1994, 49(10), 727.

[12] R.M. Silverstien, F.X. Webster, D.J. Kiemle; "Spectrometric Identification of 6th ed., John Wiley and Sons, New Yourk, USA.

[13] R.L. Shriner, C.K. Hermann, "Spectroscopic Techniques for Organic Chemistry", 2004, John Wiley and Sons, New Yourk, USA

[14] J.W. Cooper, "Spectroscopic Techniques for Organic Chemistry", 1980, John Wiley and Sons, New Yourk, USA.

[15] A. F. Abbas.," Syntheses and Characterizations of some New Pyrazolines Derived from Chalcone Compounds " ; Basrah Journal of Science (C), 2014, 32(1),118-135 